\title{
El retaule dels Osona de l'església de la Mare de Déu de Jesús (Eivissa, Illes Balears). Noves aportacions documentals
}

\author{
Antoni Ferrer Abárzuza
}

Universitat Autònoma de Barcelona

antoni.ferrer@uab.cat

Recepció: 25/01/2017, Acceptació: 27/04/2017, Publicació: 22/12/2017

RESUM

Aquest article presenta la confirmació documental de dues circumstàncies fonamentals en la història del retaule de la Mare de Déu de Jesús o de la Mare de Déu de la Llet d'Eivissa, obra de començament del segle XVI realitzada per Roderic i Francesc d'Osona. En primer lloc, queda provada definitivament la filiació franciscana de l'obra d'art i de l'església en la qual es conserva i, en segon lloc, s'ha identificat plenament la identitat del comitent de l'obra, la data de factura del retaule i la de la seva arribada a l'illa d'Eivissa.

Paraules clau:

Roderic d'Osona; Francesc d'Osona; pintura gòtica tardana; retaule de la Mare de Déu de la Llet; retaule de la Mare de Déu de Jesús; Eivissa; Illes Balears; franciscans

\section{Abstract}

Osona's altarpiece in the Church of Our Lady of Jesus, Ibiza, Balearic Islands: New evidence

This paper presents new evidence for two important events in the history of the altarpiece of the Church of Our Lady of Jesus in Ibiza, also known as Our Lady of the Milk. The altarpiece was made by Rodrigo and Francisco de Osona in the early sixteenth century. The evidence proves the Franciscan connection of the altarpiece and the church, identifies the person who received the piece, and dates the production of the work and its arrival to the island.

\section{Keywords:}

Rodrigo de Osona; Francisco de Osona; late Gothic painting; Our Lady of the Milk altarpiece; Our Lady of Jesus altarpiece; Ibiza; Balearic Islands; Franciscans 
A Gabriel Sorà

A quest article pretén aclarir els dos aspectes que fins ara s'han mantingut més foscos sobre el retaule de la Mare de Déu de Jesús o de la Mare de Déu de la Llet, del taller de Roderic i Francesc d'Osona, conservat a l'església de la Mare de Déu de Jesús d'Eivissa (Illes Balears) ${ }^{1}$. Es tracta de dues qüestions que esdevenen fonamentals per contextualitzar el retaule històricament: conèixer la identitat, la intenció i les circumstàncies del comitent de l'obra, i la data de l'encàrrec. Cap d'aquests dos aspectes no s'havia resolt fins ara, de manera que els dubtes expressats pels primers autors que tractaren sobre aquesta obra principal del patrimoni artístic insular han continuat sorgint entre els qui n'han fet escrits posteriorment. Arran de la restauració d'aquesta obra d'art durant l'any 2016 per part de l'empresa especialitzada Mitra Restaura, amb base a Mallorca, s'ha dut a terme un estudi documental paral.lel que ha proporcionat, cal dir que inesperadament, els fruits que ací es presenten².

El professor Chandler R. Post estudià el retaule anomenat abreujadament «de Jesús» en el seu volum VI, publicat el $1935^{3}$. Aquest autor va incloure, en el seu extens comentari, la proposta que l'obra podia haver estat el retaule de l'altar major de la catedral d'Eivissa durant un temps, fins que hauria quedat relegat a la seva ubicació actual. És important advertir que la catedral actual s'erigí originàriament com a església parroquial d'Eivissa i Formentera, dependent de l'arquebisbat de Tarragona, $\mathrm{i}$ ho fou fins que, el 1785 , es creà el bisbat d'Eivissa. D'altra banda, l'església de la Mare de Déu de Jesús va ser capella conventual durant un temps; després, capella sufragània de la dita parroquial; novament, conventual de dominics, $i$, finalment, temple parroquial. Isidor Macabich, canonge arxiver d'Ei- vissa durant bona part del segle $\mathrm{Xx}$, s'apressà a respondre negativament a la proposta de Post, tot argüint que el retaule major de la catedral no es documenta mai pintat, sinó escultòric ${ }^{4}$.

La conjectura de Ch. R. Post s'originà, sense cap mena de dubte, en l'acusat contrast que l'investigador nord-americà percebé entre el retaule i el lloc on acomplia la seva funció litúrgica. L'església de Jesús, propera a la ciutat d'Eivissa - vila d'Eivissa fins al $1782-$, era, en el moment de la visita d'aquell especialista $i$ ho és encara actualment, un temple petit i pobre, com ho són tots els de la part forana d'Eivissa. Els arrebossats blancs de calç interiors i exteriors cobreixen les fàbriques on són absents els carreus o altres aparells nobles (figures 2 i 3 ). El temple de Jesús no té cap més luxe que el retaule. Aquest fet suscità el convenciment de Post que aquella joia del gòtic tardà no havia estat instal-lada en la dita església de bon començament. Ara sabem que anava errat.

Abans de Post, almenys dos autors també perplexos davant de la presència d'una obra d'art tan rica en una església tan pobra en dimensions, en la fàbrica $i$ en altres ornaments, proposaren explicacions d'interès. Josep Maria Quadrado, en la seva obra de I 888 feta en collaboració amb Pau Piferrer, afirmà, referint-se al retaule, que es tractava d'una «joya de extranjero origen, flamenco probablemente, es sin duda semejante obra, aparecida sin saberse cómo ni cuándo en un país tan refractario en sus templos al arte». J. M. Quadrado atribuí aquella raresa a la llavors poc documentada presència d'una comunitat de franciscans i després de dominics en les dependències de l'església de Jesús ${ }^{5}$. Els testimonis d'admiració envers el retaule foren abundosos abans de la Guerra Civil de 1936-1939, no debades es va convertir en un dels atractius cul- 


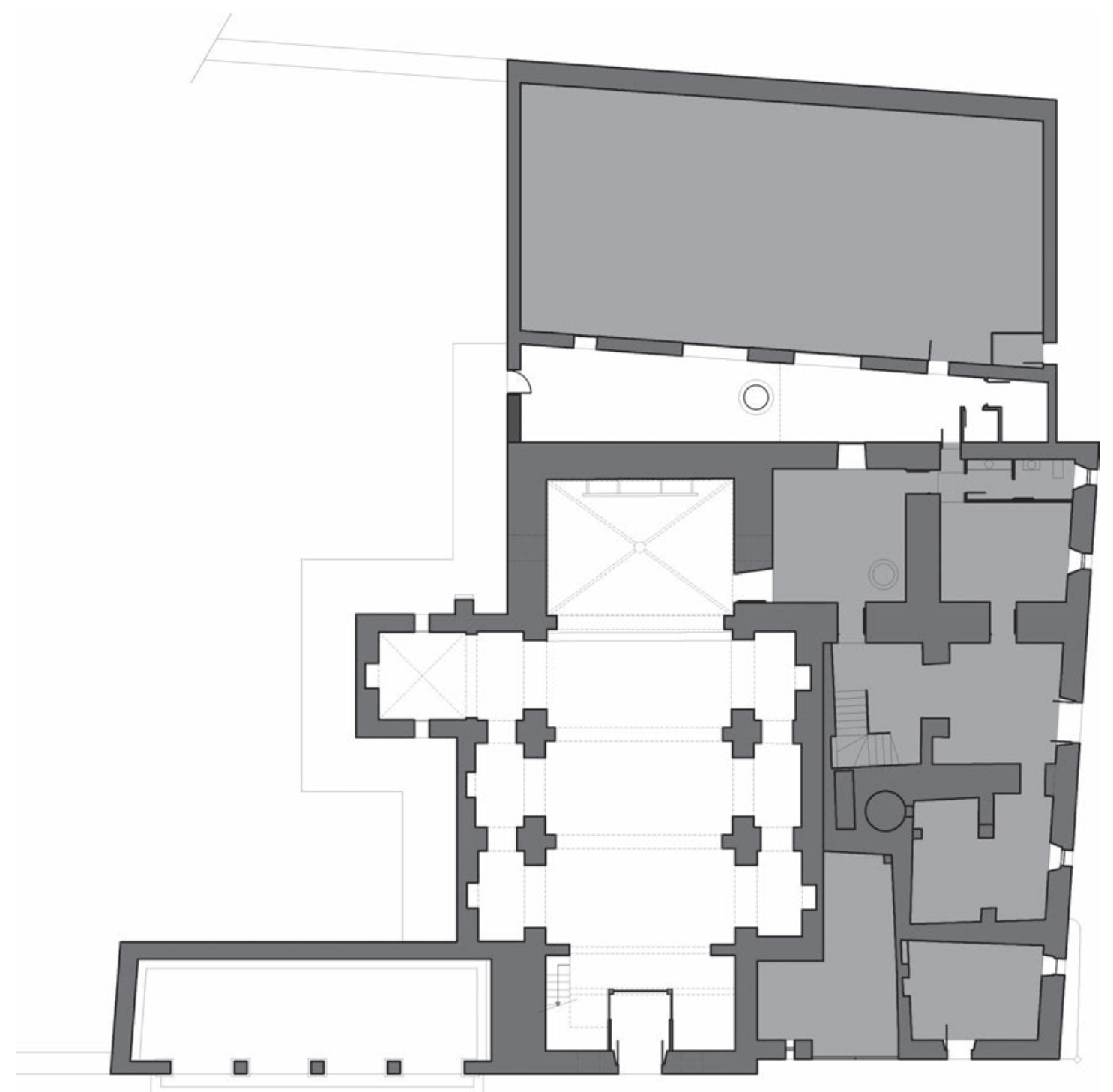

Figura 1.

Planta de l'església de la Mare de Déu de Jesús (cortesia de Toni Marí, arquitecte).

turals de l'illa. Els personatges notables que la visitaven eren portats invariablement a veure les tombes púniques del puig des Molins i l'església de Jesús. Entre ells, Santiago Rusiñol, el I9I 2, i Joaquim Sorolla, el I91 $9^{6}$.

Les notícies sobre els dominics a què es refereix Quadrado són ben conegudes?. El i 580 , l'església i les dependències annexes foren cedides a l'orde dels predicadors de Sant Domènec $\mathrm{i}$ en prengueren possessió efectiva l'i I de setembre d'aquell any ${ }^{8}$. Hi romangueren fins al I 587 , quan passaren al convent nou, construit intramurs, $i$ es desprengueren definitivament de l'església i de les cases de Jesús l'any I674, mitjançant la venda que en feren a la reverenda comunitat de preveres de la parròquia de Santa Maria. El document notarial de venda especifica que la transacció implicava «tota la casa, iglésia, edificis, patis, fosars, corrals y tot lo demés de Nostra Señora de Jesús, juntament ab los altars y quadres y ornaments que vui tenen en dita iglésia»". Alhora, el 1704, l'església i les seves dependències foren objecte d'una nova transacció. Aquella vegada, la comunitat de preveres de Santa Maria, representada per Antoni Almarge, traslladà la possessió de la «yglésia, casa, edefiçis, pati, fosar, corral y tot lo demés àmbit y siti de ella, juntament ab los altars, quadros e imàgens, ornaments y quant en ella y ha per a son adorno y perfecçió» al batlle quartoner del pla de Vila, al síndic del dit quartó i als obrers del temple $\mathrm{i}$ als seus successors en aquests càrrecs, «instituhint-vos a vos y als vostres sucçessors en dits oficis respective e simul et in solidum verdaders señors de dita yglésia, casa, fosar, pati etcètera» ${ }^{10}$. 


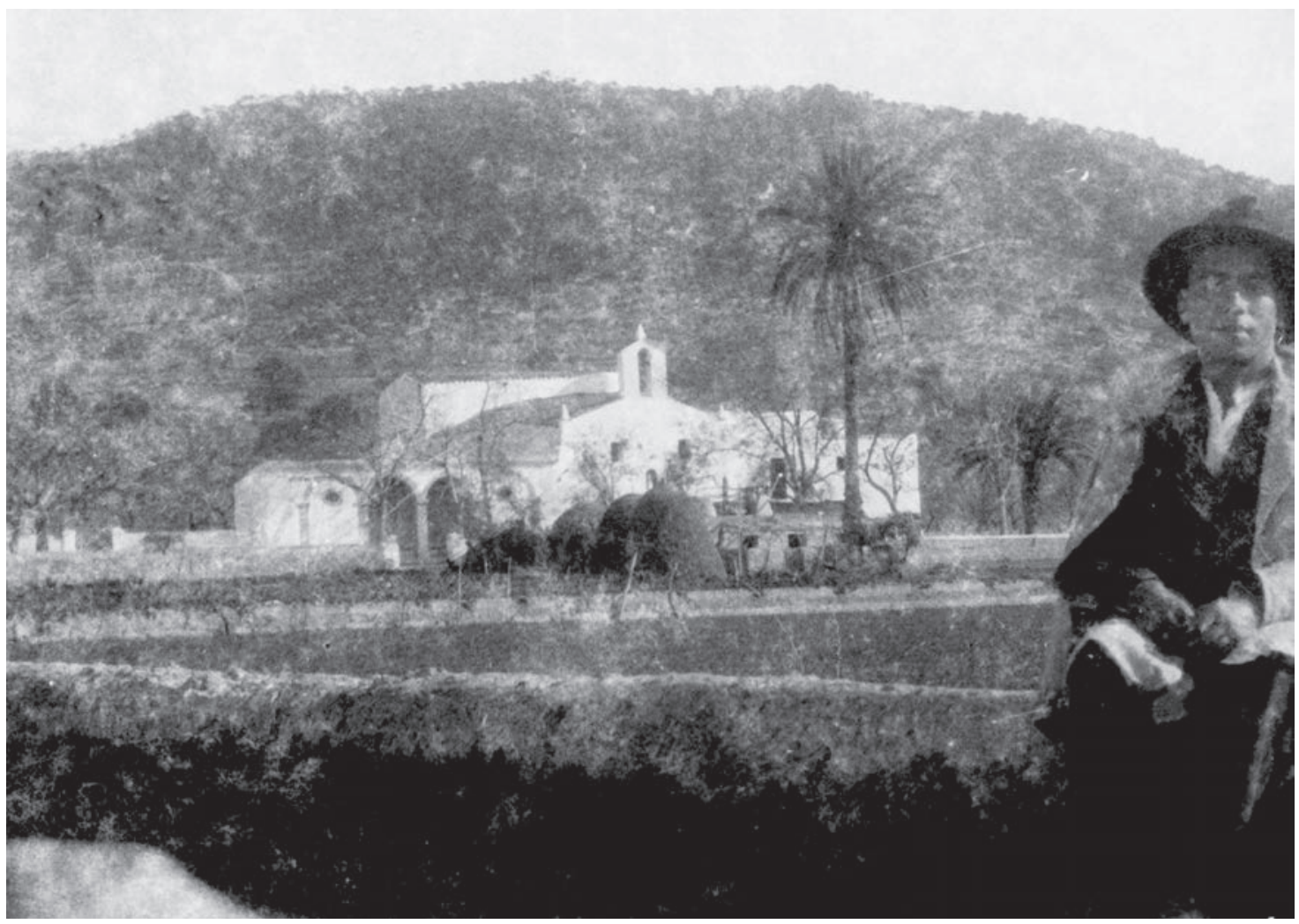

Figura 2.

L'església de la Mare de Déu de Jesús a la dècada de 1930 (arxiu particular).

És sabut que la data que s'atribueix a la producció del retaule és el final del segle $\mathrm{XV}^{11}$. Així doncs, seria clar que els dominics, prou més tardans a Eivissa, no haurien pogut haver participat en el seu encàrrec. Com s'ha dit, J. M. Quadrado esmentà també els franciscans. És una dada que prengué d'un autor anterior, Antoni Deià Tortella ${ }^{12}$, conegut com el pare Gaietà de Mallorca, qui escrigué una història d'Eivissa i Formentera que acompanyava l'edició de les ordinacions municipals de I686, feta a Mallorca el 1752. Aquest resum va ser un encàrrec de l'Ajuntament i s'hi s'assegura que el pla de Vila tenia «una Iglesia, la más principal de todas las de fuera. Fue en algún tiempo habitada de Frayles Franciscos, y aún mantiene la forma de Convento» ${ }^{13}$.

Tanmateix, però, la documentació sobre la presència d'una comunitat franciscana en el temple de la Mare de Déu de Jesús i les seves dependències es limitava aparentment a la dita nota del pare Gaietà, represa per Quadrado, i a una lacònica al·lusió del visitador eclesiàstic Joan d'Ossó, de I577, quan, en referir-se a l'església de Jesús, digué «ahon antígament solien estar frares» ${ }^{14}$. Aquells frares no podien ser els dominics, perquè eren uns quants anys posteriors, com s'ha dit, de manera que Ossó es referia, sense esmentar-los, als franciscans. Exclusivament sobre aquestes notícies s'han fonamentat les afir- macions posteriors de la presència franciscana a Jesús i l'atribució a aquest orde de la instal-lació del retaule ${ }^{15}$. Fet i fet, però, la presència d'una comunitat franciscana va quedar recollida per uns altres autors i per documents posteriors. L'obra de Domenico de Gubernatis, editada el 1685 , assegura aquesta presència franciscana a Eivissa a partir d'una butlla del papa Juli III (I 549-1 555 ). Aquest document esmenta totes les províncies franciscanes i les custòdies - una divisió administrativa inferior a la província i superior al lloc o convent- que hi havia en cadascuna ${ }^{16}$. A la província d'Aragó (es refereix a la Corona d'Aragó), hi havia set custòdies, la quarta de les quals era la de Mallorca, amb tres llocs, un a la mateixa Mallorca, un altre a Ciutadella de Menorca i el que transcriu per «Iussae, sive Imisae», aparentment, per tant, Eivissa ${ }^{17}$. Algun d'aquests testimonis textuals o la memòria de la gent foren les fonts de la citada Resumpta històrica del pare Gaietà de Mallorca. Tanmateix, diversos documents conservats a l'Arxiu del Regne de Mallorca, ja citats al seu dia per l'historiador caputxí Tarsicio de Azcona ${ }^{18}$, amplien molt la informació que teníem sobre els franciscans eivissencs.

Ara, per tant, s'ha pogut documentar en ferm la relació entre els franciscans, l'església de Jesús i el seu retaule. Concretament, aquest darrer va ser un encàrrec de la Universitat d'Eivissa, pagat 


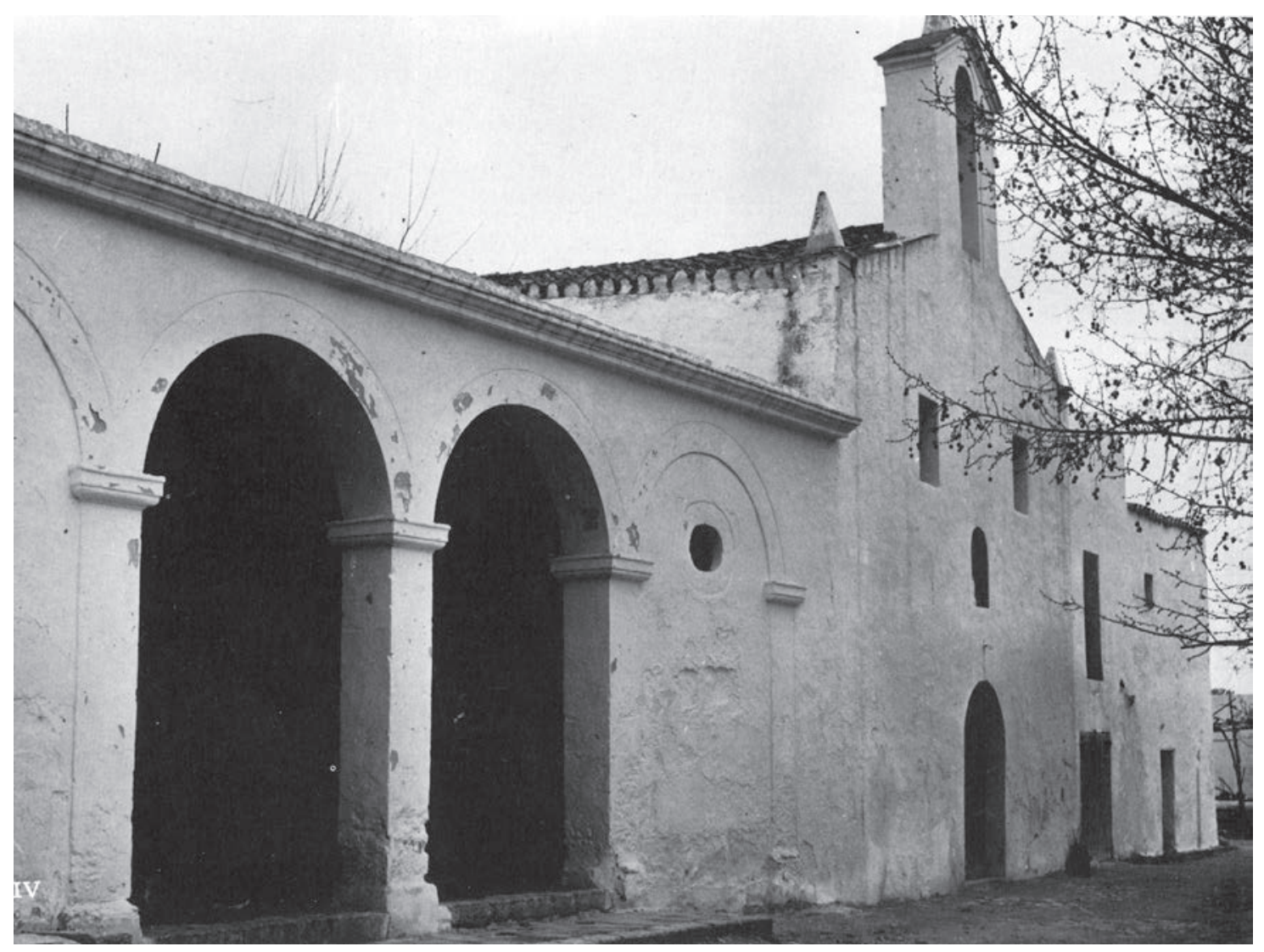

Figura 3.

Façana principal de l'església i els seus porxos de Jesús durant la dècada de 1970. Foto: Buil Mayral. Arxiu d'imatge i so municipal d'Eivissa (AISME).

el I 503 i immediatament donat o cedit a la comunitat franciscana aleshores instal.lada en el petit complex conventual. Aquell convent o monestir estigué en construcció entre I 455 i I 466, tot i que la Universitat no obtingué l'autorització papal per dedicar-lo a casa franciscana fins al I459.

\section{El temple}

El mes de maig de l'any I456, la Universitat d'Eivissa elegí Romeu Joan i Bertran Vidal com a obrers «de Senta Maria de Ihesús» ${ }^{19}$. Deu anys més tard, el Consell General elegí dos síndics, Joan Cocorella i Andreu Joan, els quals dotà d'unes instruccions que havien de seguir en el seu sindicat o visita davant del $\mathrm{rei}^{20}$. Els dos síndics s'embarcaren cap a Tortosa, on es trobava la cort, i foren rebuts efectivament pel monarca Joan II d'Aragó el mes de juliol. S'ha de recordar que, en aquell moment, feia més de tres anys que havia esclatat una virulenta guerra civil entre la Generalitat de Catalunya i el mateix rei Joan, que no acabà fins al I $472^{21}$. A més, entre I450 i I 453 , a Mallorca, s'hi havia produït l'anomenada revolta forana ${ }^{22}$. Tots dos conflictes arribaren a Eivissa, on es documenten, tot $\mathrm{i}$ que escassament, violències i bandositats ${ }^{23}$.
Els síndics feren saber al monarca les tribulacions de la Universitat i els remeis i les mesures que aquesta institució presentava a l'aprovació de sa majestat. Escoltades les demandes dels illencs i deliberades en el si del consell del monarca, es redactaren almenys tres cartes a la cancelleria reial per donar resposta a les sol-licituds dels missatgers d'Eivissa. Una d'aquestes cartes s'ha conservat en la seva forma original i les altres, en còpies $^{24}$. Això és prova que el sindicat es produí $i$ hi tingué efectes. L'altra missió dels síndics era anar a l'arquebisbe de Tarragona, Pere d'Urrea (I445-I489), al-ludit com a patriarca, perquè en fou d'Alexandria. A les esmentades instruccions que la Universitat redactà per als síndics, s'hi inclogué sol-licitar-li una autorització ben concreta: «los dits missatgers obtendran una licència del senyor patriarcha que-s puxa dir missa cascun digmenge en la iglésia que's fa en lo pla de Vila, de la Verge Maria de Ihesús» ${ }^{25}$. Aquest apartat de les instruccions està afegit després de la data, com si s'hi hagués incorporat a darrera hora. Com fos, la resposta de l'arquebisbe degué ser afirmativa, ja que el ${ }_{4} 68$ es fundà un benefici amb la càrrega de celebrar missa els diumenges a la capella de Santa Maria de Jesús del pla de Vila ${ }^{26}$.

L'advocació de l'església en obres ja es tenia ben clara: la Mare de Déu de Jesús o Nostra 
Dona de Jesús. S’ha de tenir present que el convent franciscà de Nostra Senyora dels Àngels de Jesús de ciutat de Mallorca va ser fundat l'any I 444 ${ }^{27}$; el de Jesús de Sóller, el I 458, i el també de Jesús de Maó, el I45928. Antoni Furió, en el seu llibre de i 85 I dedicat al franciscà fra Bartomeu Catany, fundador dels convents esmentats i de l'Hospital General de Ciutat de Mallorca (1456), transcriu el fragment dels annals de fra Lukas Wadding que tracta de la fundació dels convents de Maó i d'Eivissa ${ }^{29}$. L. Wadding edità una butlla del papa Pius II (I458-I464), datada a Màntua el 22 de setembre de I459, per la qual es concedia la facultat d'edificar cases de franciscans observants als habitants de Menorca i d'Eivissa; també la que elevava a custòdia franciscana les cases de les illes Balears, de primer de novembre de $1459^{30}$. En aquesta darrera butlla, se citen les cases de ciutat de Mallorca; la de Sóller, de la qual es diu que està en construcció, i les de Menorca i d'Eivissa, que tenien llicència per edificar-se ${ }^{31}$.

La primera de les dues butlles esmentades assegura que els habitants de Menorca i d'Eivissa s'havien adonat dels beneficis que havia reportat la fundació del monestir dels framenors observants de Santa Maria dels Àngels a ciutat de Mallorca i que, vist que a les dites dues illes no hi havia cap casa dels dits frares, s'oferiren a construir-n'hi. Tenien, digueren, l'esperança d'obtenir fruits semblants als collits a Mallorca en forma de pacificació de les enemistats i de les discòrdies que s'hi patien. La manera com una comunitat franciscana podia collaborar a tal fi és tota una altra qüestió. El parer papal, després de consultar l'arquebisbe de Tarragona per al cas d'Eivissa $\mathrm{i}$ el bisbe de Mallorca per al de Menorca, en fou favorable i concedí que es fessin tals cases noves de framenors: «ut singulas domos hujusmodi, in singulis Majoricen [error, per Menorca] et Iviçae Insulis prefatis, et locis ad id congruentibus et honestis cum ecclesia, claustro, coemetorio, dormitorio, refectorio, hortis, hortalitiis, et aliis necessariis officinis construere aut construi et aedificare facere». El professor Bartolomé Escandell es demanà, a la seva obra, si la presència de franciscans a l'església de Jesús d'Eivissa es devia a una iniciativa de la Universitat ${ }^{32}$. Ara queda clar que sí. Aquest mateix autor n'explicà les causes, que estaven relacionades amb la renovació religiosa que encapçalaven els franciscans observants, i insistí en la significació històrica local de la fundació d'una casa franciscana a Eivissa ${ }^{33}$.

Acceptats els precs de menorquins i d'eivissencs, en teoria, les universitats respectives podien començar la construcció dels futurs convents per tal que, un cop acabats, els frares de l'orde franciscana els ocupessin i hi pogues- sin residir perpètuament. En realitat, però, el fet que la primera notícia del convent franciscà de Maó sigui del mateix I 459 i, sobretot, que hi hagi informació sobre la voluntat de fundar una casa franciscana a Eivissa des de I455, mostra que les gestions i potser el començament de les edificacions a totes dues illes es degueren produir uns quants anys abans. Tot apunta que foren impulsades per fra Bartomeu Catany en la seva voluntat d'estendre l'orde seràfic (els framenors o franciscans) a les illes del Regne de $\mathrm{Mallorca}^{34}$, malgrat que aquestes dades no s'havien utilitzat mai per explicar la història de l'església de Jesús d'Eivissa.

Noteu que la butlla esmenta el convent de Santa Maria dels Àngels o el convent de Jesús extramurs de ciutat de Mallorca, del qual avui en queden algunes ruïnes ${ }^{35}$. La situació extramurs és compartida amb l'església de Jesús d'Eivissa i, igualment, la ubicació en un entorn agrícola ric, una necessitat prescrita pel mateix papa en manar que els nous convents de $\mathrm{Me}$ norca i d'Eivissa havien de tenir hort. A Eivissa, l'hort s'obtingué a partir d'un pou dotat d'una sénia, encara avui existent tot just davant del temple i documentat des de $1584^{36}$. No debades, aquell indret era conegut almenys des de la segona meitat del segle XV com «lo Seniar», sens dubte per l'abundància d'aquests ginys elevadors d'aigua per al reg que hi havia ${ }^{37}$. No sabem a qui pertanyien aquelles terres de jurisdicció reial abans de ser traspassades per venda o per donació a la Universitat. A les mènsules de la jàssena que suporta el cor de l'església, l'escut dels Francolí està fet en relleu i la pica d'aigua beneïda té el senyal d'un ocell, atribuït als Vidal ${ }^{38}$. Totes dues foren famílies benestants documentades als segles XV i XVI i que disposaven de vasos funeraris a l'església parroquial, avui catedral, les làpides esculpides dels quals s'hi han conservat ${ }^{39}$.

La butlla d'autorització de la fundació d'un monestir franciscà a Eivissa assegura que la petició va ser iniciativa dels seus habitants. Darrere d'aquests «habitants», penso que hi hem de veure els membres del seu òrgan de regiment municipal: la Universitat. Com en altres indrets de la Corona, a Eivissa, aquesta institució fou profundament reformada per la monarquia, amb la intenció d'obrir-la a una quantitat més elevada de ciutadans, amb la introducció del sistema de regiment de sac i sort o d'insaculació, de $1454^{40}$. Si les noves comunitats franciscanes havien de procurar la pacificació de les enemistats $\mathrm{i}$ discòrdies que esmenta la mateixa butlla — «ad inimicitiarum et discordiarum inibi vigentium sedationem»-, l'edicte reial de I 454 també s'havia referit als «scàndils, hoys e inconvenients» ${ }^{41}$. El rerefons era la revolta fora- 
na de Mallorca, començada el I450, mentre que, llavors, la guerra civil estava encara per arribar.

Tanmateix, després de les esmentades notícies que al-ludeixen a la casa franciscana d'Eivissa, les dades posteriors es limiten a parlar dels registres dels pagaments anuals que la Universitat feia als priors - sacerdots seculars - que tenien encomanada la celebració dels oficis divins en el temple. És el cas del prevere Toni Rata, «prior de la Verga Maria de Jesús», el I $483^{42}$, i d'Antoni Avinent, «prior de nostre Dona de Jesús», el I $493^{43}$. D'altra banda, en el Llibre de guardià de la sal de 1495, Isidor Macabich hi va trobar partides de sal venudes a benefici de «Nostra Dona de Jesús ${ }^{44}$. Els diners resultants anaven a manera de donació a la dita església, per mantenir-ne l'obra i el sacerdot que hi hagués destinat.

Aquestes notícies mostren que encara no hi havia clergat regular a Jesús, sinó que el temple era regit per sacerdots seculars. Això no obstant, els jurats de Mallorca ja anunciaven temps endarrere, el I 460, la creació prevista d'una casa franciscana a Eivissa. Sens dubte, la intenció dels jurats mallorquins era mostrar que hi havia cases d'aquest orde a les tres illes majors, cosa que donava més força a la seva petició al rei perquè demanés al sant pare una vicaria franciscana pròpia de les Illes: «supplicam a vostra magestat li plàcie scriure al Sant Pare que plàcie a Sa Santedat fer vicariat per sí de Mallorques, Manorcha e Eyvissa» ${ }^{45}$. La previsió era massa optimista, tot $i$ que no hi ha dubte que indica l'existència de converses per a la instal-lació de franciscans a Eivissa. El fet és que, l'octubre de I492, els mateixos jurats mallorquins, intentant encara aconseguir una custòdia franciscana pròpia, reconeixien que el monestir franciscà d'Eivissa era només una intenció: «que a tots aquests monestirs, e encara en hun altre que-s volrà fer en la vostra illa de Eviça, presidís hun custodi ${ }^{46}$. Aquells monestirs de framenors observants eren el de Santa Maria dels Àngels de Jesús, de ciutat de Mallorca; el de la Mare de Déu de Jesús, de Sóller, i el de la Mare de Déu de Jesús de Natzaret, de Maó.

Certament, els franciscans d'Eivissa no figuraven encara per enlloc i sí, en canvi, els pagaments a sacerdots seculars a càrrec de l'església de Jesús, com ja s'ha vist. Aviat, però, deixa de ser així i el Llibre de clavaria de I498, actualment perdut però que va ser consultat per Enrique Fajarnés Tur i per Isidor Macabich, recollia el pagament fet a «frare Nofre Romero, de Ntra. Dona de Ihs.» per predicar la quaresma ${ }^{47}$. Si bé és cert que els predicadors de quaresma eren generalment religiosos de fora de l'illa als quals es pagava allotjament i manutenció, tal com registren els llibres de comptabilitat de la Universitat diverses vegades, i que només hi

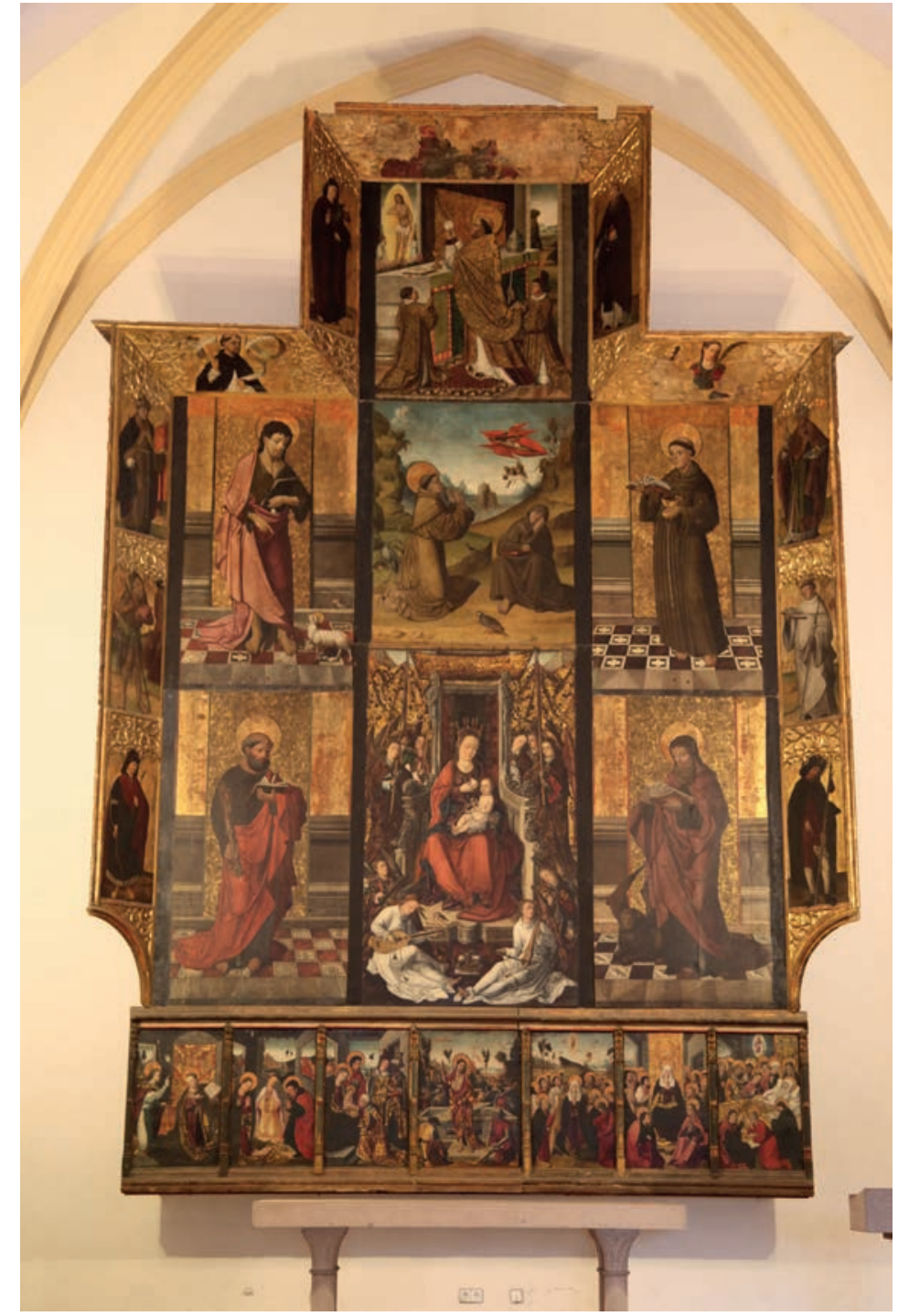

Figura 4.

Vista general del retaule de la Mare de Déu de Jesús. Foto: Mitra Restaura, SL.

feien estada durant aquell temps de l'any, en aquest cas, l'aclariment que frare Onofre era «de Nostra Dona de Jesús» s'ha de prendre estrictament $i$ considerar que hi residia de manera habitual. De fet, fra Onofre Romero era franciscà observant i n'està documentada la presència en l'acta de fundació del monestir de Santa Maria de Jesús, de Lleida, el I $477^{48}$. D'això, se'n dedueix que el convent de Jesús d'Eivissa estava habitat pels franciscans en aquella data.

El I 499, arran de les exèquies generals per l'ànima de la princesa Isabel, reina de Portugal, es pagaren - segons I. Macabich, qui es basa en l'esmentat Llibre de clavaria de I498- uns diners «per lo clero e frare de Jhs.» ${ }^{49}$. També Macabich rescatà la dada, però sense citar-ne la font, del pagament fet per la Universitat a «Fra Bernadí» per ser prior de l'església de la Mare de Déu de Jesús ${ }^{50}$. És interessant fer notar que, 


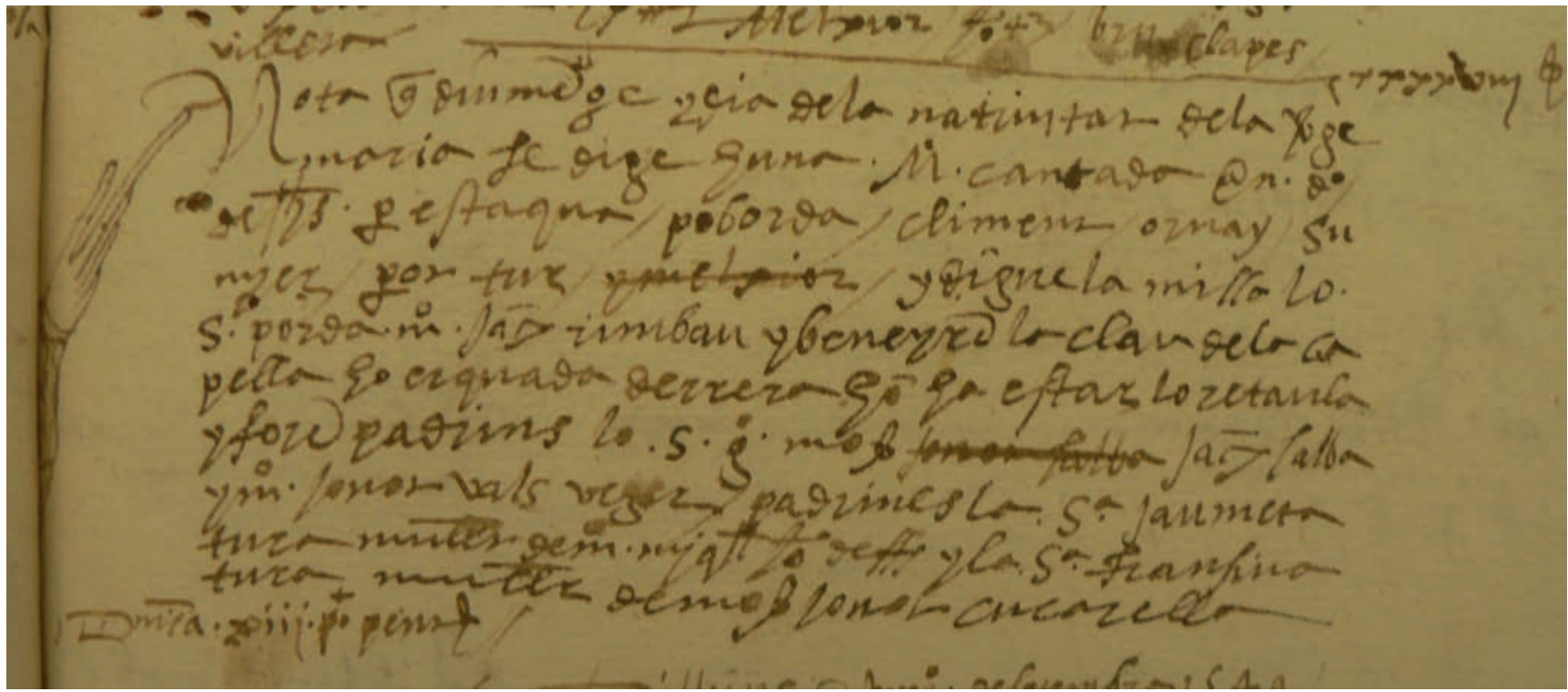

Figura 5

Nota manuscrita, inclosa en els Llibres d'entreveniments, de la benedicció de la clau de la volta del presbiteri de l'església de Jesús, 8 de setembre de 1549. Foto: F. X. Torres Peters, Arxiu Històric de la Pabordia d'Eivissa, AHPE.

el I 499, el text es refereix al frare, en singular, i, igualment, el i so5, s'al-ludeix a un sol religiós. Això pot donar idea de la migradesa de la comunitat - si se'n pot dir així- de la Mare de Déu de Jesús d'Eivissa.

Isidor Macabich ja va veure clar que, en els primers temps de la història de l'església de Jesús, hi hagué dos moments clarament diferenciats. El primer abraça de la primera notícia de I 455 fins que el temple passà del clergat secular al regular, entre I493 i I 498, i el segon correspon a l'època dels dominics, ja esmentada. Ara sabem que, des de la seva naixença, l'església de Jesús tenia relació amb els franciscans i que, per tant, s'edificà com a casa de religiosos regulars $i$ no com a església o capella sufragània de la parroquial, com sí que ho eren unes altres capelles de la ruralia de l'illa. No coneixem les circumstàncies per les quals l'edifici no va ser ocupat immediatament pels franciscans, però poden endevinar-se: dificultats econòmiques i d'organització del mateix orde, falta de disponibilitat de personal o bé que la Universitat d'Eivissa no aconseguí acabar les dependències conventuals d'acord amb els mínims necessaris. S'ha de recordar que la butlla de I 459 especifica tota una sèrie d'àmbits: església, claustre, menjador, dormitori i refetor. No s'ha de pensar en un gran edifici, però la més mínima versió d'aquestes construccions ja significava una despesa important per a unes arques municipals finançades constantment a força de crèdits.

Com també el mateix I. Macabich proposà, aquella comunitat franciscana s'hauria extingit o s'hauria traslladat abans de I 5 I 2, ja que, a par- tir d'aquell any, figuren cobrant de la Universitat, per ser els priors de Jesús, diferents sacerdots seculars: el i 5 I 2, «el discret Jacme Sunyer, prevere» ${ }^{51}$; el I 5 20, «mossèn Berthomeu Fluxà», $\mathrm{i}$ «mossèn Perot Tur, prevere» els anys $\mathrm{I} 527^{52}$, I $534^{53}$, I $537^{54}$, I $539^{55}$, I $543^{56}$, I $544^{57}$, I $547^{58}$, I $548^{59}$ i fins al I555, quan fou substituït per Antoni Joan, perquè ja era "vell y possat en senectut» ${ }^{60}$. La crisi entre franciscans conventuals o claustrals i els observants i els dubtes sorgits en el mateix moviment observant pogueren causar l'abandó del reduït convent d'Eivissa ${ }^{61}$. Amb les dades que tenim, la presència franciscana a Eivissa se circumscrigué al lapse temporal afitat entre I 498 i I 5 I 2.

\section{El retaule a Jesús}

Una vegada aportats documents que acrediten la fundació del convent franciscà d'Eivissa amb seu al pla de Vila, a l'església i a les instal-lacions conventuals de la Mare de Déu de Jesús, cal abordar les noves sobre la presència del retaule en el dit temple i la seva relació amb els frares franciscans (figura 4).

Ximo Company, coneixedor de les dates de producció del taller de Roderic d'Osona i de les notícies locals sobre el temple de Jesús, va considerar que «l'establiment dels franciscans l'any $\mathrm{I} 498 \mathrm{fa}$ ben versemblant la contractació d'aquest retaule en l'esmentada data o, almenys, no gaire temps després» ${ }^{62}$. Veurem com, gràcies a certs documents ara localitzats, s'ha pogut contrastar l'encert d'aquesta deducció. El pri- 


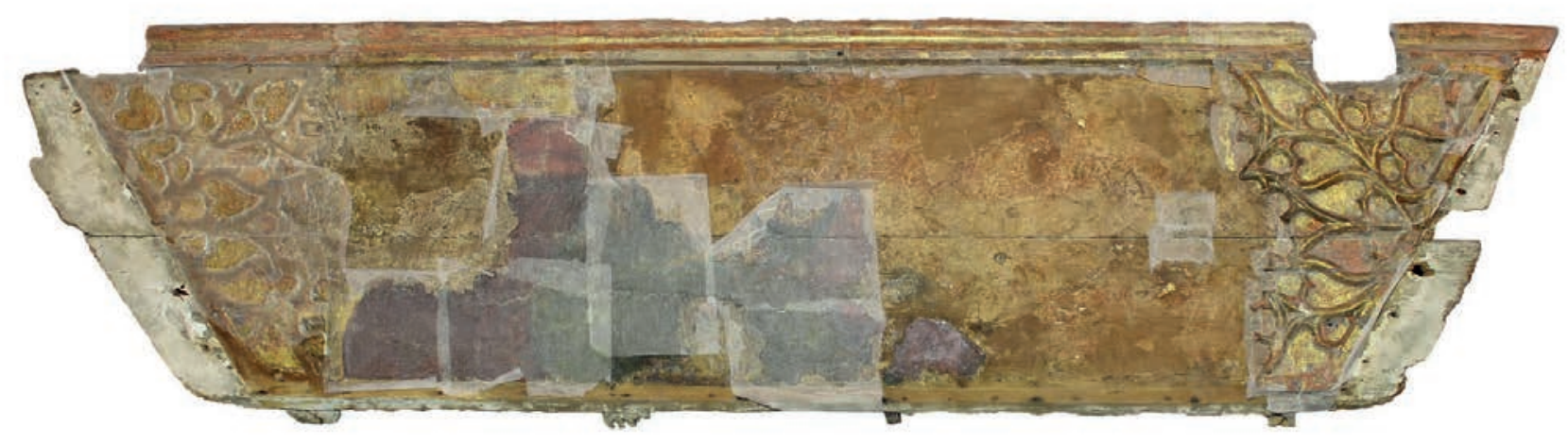

Figura 6.

Taula superior de la polsera del retaule de Jesús, amb les mosses a la part superior. Foto: Mitra Restaura, SL.

mer esment que fins ara es coneixia del retaule data del dia 8 de setembre de I 549 i es conté en una nota dels anomenats Llibres d'entreveniments o d'intervencions dels preveres de l'església parroquial, que inclouen una mena d'annals (figura 5). Diu així:

Nota que diumenge y dia de la Nativitat de la Verge Maria se digé huna missa cantada a Nostra Dona de Jesús. Per estaqua: poborda, Climent, Orvay, Sunyer, Perot Tur y Metxior. Y digué la missa lo senyor po(bo)rda, mossèn Jaume Rimbau, y beneyren la clau de la capella ho erquada derrera, hon ha estar lo retaula, y foren padrins lo senyor governador, mossèn fonot Salbà Jaume Salbà, y mossèn Jonot Vals, veger; padrines la senyora Jaumeta Tura, muller de mossèn Miquell Joan de Francesc, y la senyora Fransina Tura, muller de mossèn Jonot Cucarella ${ }^{63}$.

Actualment, el presbiteri de l'església de Jesús està cobert per una volta de creueria que s'aixeca sobre la seva planta rectangular. A la clau de volta, s'hi llegeix el monograma IHS -Jesús-. La resta del temple està cobert per una volta de mig canó bastant imperfecta o deformada que descansa sobre arcs faixons apuntats. La volta pot correspondre a unes obres de reforma molt importants que hi tingueren lloc al segle XIX i que implicaren l'enderrocament de «la torre contigua a la iglesia» el I8 8 i una intervenció integral el $1862^{64}$.

És lícit pensar que la volta del presbiteri, acabada el mateix I 549 o poc després, és la que es conserva actualment, efectivament aixoplugant el retaule dels Osona, i que aquest retaule és el mencionat a la nota. La retirada dels arrebossats exteriors i interiors dels murs del presbiteri n'ha posat al descobert l'aparell anomenat en espina de peix (hereu de l'opus spicatum dels romans) molt ben executat en pedra ${ }^{65}$. Diferents cons- truccions d'Eivissa, especialment les torres de defensa o de refugi, foren aixecades majoritàriament utilitzant aquesta tècnica $i$, com el dit presbiteri, es daten durant el segle $\mathrm{XVI}^{66}$. De la nota, se'n pot deduir aparentment que l'obra es va fer adossant la nova volta a la resta del temple $i$, per tant, la nau va ser allargada per la capçalera. La unió de la nau i el nou àmbit cobert de volta de creueria només pogué aconseguir-se enderrocant el mur de capçalera antic, contra el qual es degué instal-lar el retaule originàriament. L'arqueologia haurà d'aclarir aquest extrem, entre d'altres, durant les obres previstes de restauració del temple ${ }^{67}$.

Així doncs, el I 549, el retaule va ser traslladat, encara que només fossin uns quants metres, dins del mateix temple. Gràcies a aquesta informació $\mathrm{i}$ a les circumstàncies del mateix retaule, es pot deduir una dada d'interès per a la història de l'església de Jesús. La taula central i superior del guardapols o de la polsera del retaule presenta dues mosses o escotadures prop dels cantons i aproximadament simètriques respecte a l'eix central de la taula (figura 6). Les fotografies més antigues, anteriors a la Guerra Civil de 1936-193968, ja mostren aquestes dues petites mutilacions en la dita taula. La interpretació que faig d'aquestes mosses és que corresponen a la solució que es donà a la falta d'alçada de l'església en el moment de muntar el retaule al començament del segle XVI. La dita taula superior de la polsera hagué de ser encaixada entre dues bigues o dues peces de l'enteixinat d'una coberta diferent de l'actual de la nau - la del presbiteri ja la sabem de I 549, com s'ha dit-. Molt probablement, i això també s'hauria de comprovar per mitjà de l'arqueologia de paraments, la coberta corresponent a aquella fase era d'embigat de fusta. Els arcs apuntats actuals de la nau correspondrien als arcs diafragma que suportaven aquestes bigues, que estarien posades en la mateixa 


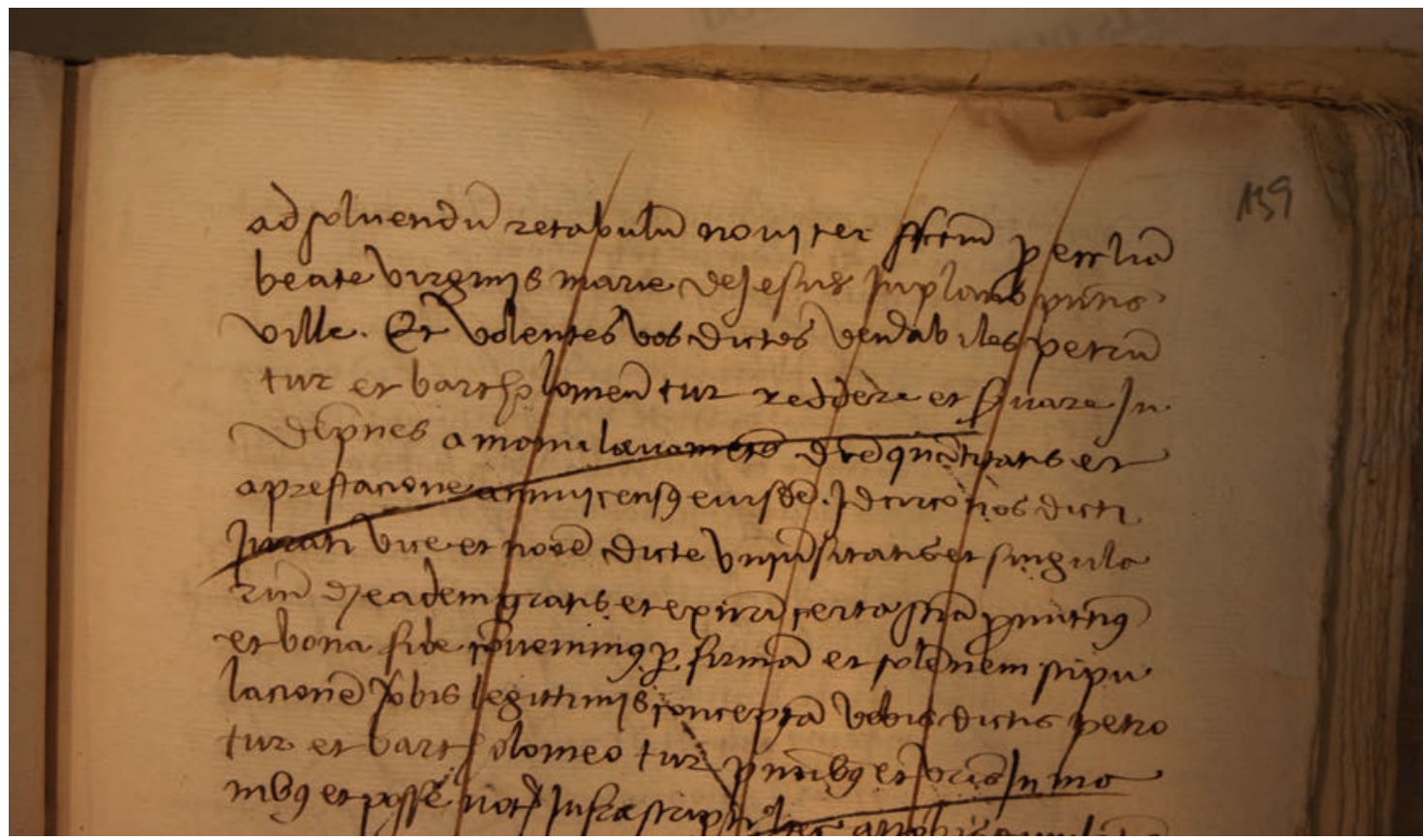

Figura 7.

Fragment del contracte de carregament de censal per a la compra del retaule, datat el 14 de gener de 1503. Foto: A. Ferrer, Arxiu Històric d'Eivissa, AHE.

direcció que la nau. El mal estat d'aquella coberta, l'original del temple, degué malmetre la dita taula superior de la polsera - que, de fet, ha perdut la capa pictòrica quasi totalment ${ }^{69}-$ i va fer recomanable la construcció d'una volta que aixoplugués millor el retaule, cosa que es va fer el i 549 amb la construcció de la dita volta de creueria.

Com ja s'ha avançat unes quantes línies més amunt, l'estudi documental que ha acompanyat la restauració del retaule ha permès obtenir informació del tot inèdita sobre aquesta obra d'art (figura 7). Ara sabem que el finançament va anar a càrrec de la Universitat d'Eivissa, cosa que demostra que la sol-licitud feta al papa Pius II abans esmentada va sortir de l'òrgan de regiment municipal. El i4 de gener de I 503, la Universitat va emprar cent lliures en moneda reial del Regne de Mallorca destinades «ad solvendum retabulum noviter factum pro ecclesia Beate Virginis Marie de Jesus in plano presentis ville» ${ }^{70}$.

El pagament del retaule es féu, com era habitual en les finances de la Universitat en aquella època, mitjançant la venda d'un censal de vuit lliures, sis sous i vuit diners anuals pel preu de cent lliures, tot en moneda reial de Mallorca. La data d'aquest document notarial de venda del censal és I 4 de gener de I 503 , es conserva en el Llibre d'actes $i$ contractes de la Universitat de I499-I 5 IO i s'hi contenen dos documents consecutius fets el mateix dia. En el primer, Pere Tur, fill de Joan, i Bartomeu Tur, fill de Llucià, membres del consell secret de la Universitat, s'obligaven personalment a mantenir les clàusules de contracte. Aquesta obligació personal va ser aixecada per mitjà del document següent, en el qual els jurats d'aquell any, Llucià Tur, Climent Joan i Bartomeu Joan, preservaven els béns d'aquelles dues persones i obligaven els béns de la Universitat en lloc seu.

L'operació, en termes actuals, va consistir en un préstec de 24.000 diners (que són 2.000 sous, equivalents a roo lliures) que demanà la Universitat, prestatària, a canvi d'una renda anual de 2.000 diners procedents de les arques municipals assignada al prestador, que va ser l'honorable Joan Serra ${ }^{71}$. Aquesta renda significa un interès del $8,33 \%$ anual. La diferència amb un préstec ordinari era que la renda o el cens anual no tenia un termini estipulat i, per tant, era perpètua $i$ hereditària fins que el prestatari tornava la mota o quantitat prestada, de manera que es quitava o es cancelllava el censal. Aquest censal no es va quitar o cancelllar - és a dir, que es tornaren els diners emprats als hereus del dit Joan Serra - fins al i 575 . Això significa que la Universitat va pagar els 2.000 diners anuals entre I 503 i i 575 .

El càrrec inicial del censal, cent lliures, era d'un valor relativament baix si es compara amb la generalitat dels emprèstits que sol-licitava el comú. En efecte, aquella anyada de I 502 a I 503 la Universitat va fer despeses importants en l'adquisició de blat: una de 465 lliures a canvi d'un $8,25 \%$ anual «pro emendis frumentis» $\mathrm{i}$ 
una altra de 850 lliures al $8,35 \%$. En general, aquestes operacions de més muntant es cancellaven al cap d'un any o dins dels dos o tres anys següents. En el cas del retaule, ja s'ha vist que no fou així.

Una altra qüestió és si tal quantitat de diners era el muntant total del retaule o un dels terminis d'un pagament fraccionat eventual, ja que era habitual satisfer el preu acordat per contracte notarial en tres terminis lliurats, respectivament, a l'encàrrec, a la meitat i a l'acabament i la instal.lació de l'obra ${ }^{72}$. El document no fa constar que es tracti del pagament d'un termini, sinó que afirma que les cent lliures «serviren i foren convertides en el pagament del retaule». En una altra operació de venda de censal anterior, de 2 I de desembre de i $50 \mathrm{I}$, es manllevaren noranta lliures i s'especificà clarament que eren a compliment de les cent noranta lliures que costaven certes vestes - «capa et vestimenta brucatus albi noviter facta fuere in civitate Valencie»- per a l'església parroquial ${ }^{73}$.

Així doncs, eren cent lliures un preu suficient per a un retaule de les característiques del conservat al temple de la Mare de Déu de Jesús d'Eivissa? El primer que cal tenir present és que les cent lliures del document de $\mathrm{I}_{5} \mathrm{O}$ corresponien a moneda del Regne de Mallorca. Feta l'equivalència a moneda del Regne de València, resulten una mica més de 67 lliures, això són $\mathrm{I} .340$ sous $^{74}$. Ximo Company publicà que el preu concertat amb Roderic d'Osona per al retaule de la Crucifixió de l'església de Sant Nicolau de València fou de trenta lliures que calia pagar en tres terces. En canvi, el retaule del mateix mestre destinat a Nules (Castelló), avui perdut però que era dedicat a sant Bartomeu i a sant Jaume, fou contractat per I 80 lliures també pagadores en tres terminis. En aquell preu, s'hi incloïa un tabernacle daurat que havia de tenir el retaule. El cardenal Roderic de Borja, futur papa Alexandre VI, encarregà un retaule a Roderic d'Osona, un dels pagaments fets pel cardenal fou de cent lliures $i$ un altre de cinquanta, de la qual cosa se'n suposa un preu de cent cinquanta lliures o més, si hi hagué un tercer pagament. Ara bé, el retaule de Sant Dionís de la seu de València, obra de Roderic i Francesc d'Osona, es contractà l'any i 500 per cent setanta-cinc lliures, i el pare i el fill en cobraren finalment dues-centes ${ }^{75}$.

Miguel Falomir, a partir del cost total de diferents retaules de mitjan segle $\mathrm{XV}$, estima que el metre quadrat de fusta, pintura i acabats oscil-lava entre les quatre $i$ les cinc lliures de València. El retaule d'Eivissa té a l'entorn de 28 metres quadrats, de manera que podria haver costat entre I I 2 i I 40 lliures valencianes, és a dir, unes I67 i 209 lliures de Mallorca, res- pectivament. Naturalment, això variava segons els pigments utilitzats $\mathrm{i}$ els acords específics respecte al trasllat i al muntatge de l'obra d'art. De moment, no disposem del contracte d'encàrrec del retaule eivissenc, de manera que en desconeixem aquests extrems ${ }^{76}$. Arran d'aquests càlculs, podem deduir sense gaire seguretat que la quantitat de cent lliures mallorquines de la venda del censal de gener de 1503 no bastava per al pagament de la totalitat del retaule, sinó, si de cas, de la seva meitat.

Pel que fa a la data d'arribada del retaule a Eivissa, s'ha d'entendre estrictament el document de carregament de censal, que es refereix al «retabulum notiver factum». Probablement, per tant, els diners eren el pagament final de l'obra d'art i del seu muntatge. El retaule que s'ha esmentat abans, el de Sant Dionís de la seu de València, fou encarregat als Osona el I9 de març de I 500, i els dits pintors l'entregaren el 25 de juny de $1502^{77}$. El temps de creació d'un retaule depenia, lògicament, de les qualitats $i$ de la grandària, però és lícit suposar que el retaule de la Mare de Déu de Jesús d'Eivissa es va començar a fer a l'obrador dels Osona, sota encàrrec de la Universitat d'Eivissa formalitzat dins dels primers mesos de I50I, quan el retaule de Sant Dionís de València encara no estava acabat.

\section{Conclusions}

El I459, les universitats d'Eivissa i de Menorca varen rebre de Roma l'autorització per a la creació de dues cases franciscanes observants a les dites illes, tot seguint l'exemple de Mallorca. Aquesta coordinació s'ha de deure a la figura de fra Bartomeu Catany, qui va introduir l'observança franciscana a les Illes. De fet, uns quants anys abans, el I455, els jurats de Mallorca ja preveien la construcció de cases franciscanes a totes les illes Balears. Immediatament, el I 456 es té la primera notícia de la construcció d'un temple a Eivissa, extramurs, al pla de Vila, dedicat a la Mare de Déu de Jesús. L’arribada dels frares trigà una mica més, i el 1492 encara era un projecte. El I498, aquella previsió s'havia materialitzat $i$ es documenta el nom d'un frare franciscà observant fent residència a Jesús: frare Onofre Romero, qui havia estat present en la fundació del monestir de Lleida el i 477. Des d'aleshores, la casa d'Eivissa serà afegida a les llistes de llocs franciscans i quedarà inclosa en la custòdia o vicariat franciscà del Regne de Mallorca. La presència franciscana a Jesús va ser curta: havia finalitzat el is I2, quan es tornen a documentar sacerdots seculars com a priors en aquella església. 
La Universitat d'Eivissa, que havia fet força per aconseguir que hi pogués haver franciscans a l'illa, va voler sufragar el cost d'un ornament important per a la capella del convent de Jesús: un retaule comprat a València. L'encàrrec es féu als mateixos pintors les obres dels quals eren instal-lades a la catedral de València i que rebien encàrrecs del cardenal Borja. Així, el I4 de gener de I503, la Universitat obtingué cent lliures mallorquines pel procediment de la venda d'un censal o renda anual perpètua de dos mil diners. Molt probablement, per tant, la data d'arribada del retaule de Roderic i Francesc d'Osona a Eivissa és l'any i 503 . Com es pot veure, aquesta data coincideix amb el lapse en què es documenta la presència de frares franciscans a l'església de Jesús. La dedicació principal i la iconografia general del retaule lliguen plenament amb aquesta circumstància. Clarament, doncs, l'obra d'art va ser encarregada i pagada per la Universitat amb la intenció d'instal-lar-la en el convent franciscà, del qual s'esperaven, potser debades, tants beneficis espirituals. 


\section{Apèndix documental}

Censal del honorable Johan Serra de Bernat de VIII lliures, VI sous, VIII diners ${ }^{78}$.

Die XIIII januarii anno a Nativitate Domini millesimo D secundo ${ }^{79}$.

In Dei nomine amen. Noverint universi quod nos, Petrus Tur, filius Johannis, quondam, et Bartholomeus Tur, filius Luciani, habitatores Evice, de consilio secreto universitatis Evice ambo, simul et uterque nostrum in solidum, per nos et nostros presentes et futuros, cum auctoritate et decreto magnifici et honorabilis Bernardi Pau Çalba, domicelli, consiliarii ${ }^{80}$, coperii regis nostri domini et pro sua regia majestate gubernatoris; Bernardi Tur, bajuli Evice pro reverendissimo domino Archiepiscopo, et Michaelis Pons, bajuli Evice pro reverendissimo capitulo Terrachone per obitum reverendissimi prepositi, non dolo vi vel metu inducti, seducti nec in aliquo circumvenenti, ymo gratis et ex nostris certis scienciis, vendi muset titulo huiusmodivendicionis concedimus, tradimus corporaliter seu quasi vobis, honorabile ${ }^{81}$ Johanni Serra, filio Bernardi, quondam, conhabitatori nostro, presenti et acceptanti, et vestris, octo libras sex solidos et octo denarios re(galium) $\mathrm{Ma}$ (ioricarum) mi(nutorum) censuales annuales et rendales per nos et nostros presentes et futuros vobis et vestris solvendas et deliberandas a die qua presens constitutur instrumentum ad unum annum et de inde annis singulis in eadem die sive termino die a diata sine omni dilacione, excepcione, dampno et missione, interesse et gravamine vestri et vestrorum, ac curie querela. Nam si per predictis annuo censu a nobis petendo, habendo, exhigendo et recuperando opportuerit, vos vel vestros aliqua dampna, gravamina, missiones, sumptus, interesse et expensas, judicio et extra qualitercumque subire, sustinere sive pati, nos ea omnia vobis et vestris solvere, restituere et emendare promittimus ${ }^{82}$ debeamus et teneamur incontinenti vestre omnimode voluntati de et super / quibus dampnis, gravaminibus, sumptibus, missionibus, interesses et expensis credatur credique volumus vobis et vestris sola, plano, simplici verbo sine testibus et juramento et judiciaria tatxacione quantumque inde minime requisita vel expectata quasquidem octo libras, sex solidos et octo denarios censuales annuales et rendales vobis assignamus ac de novo imponimus et carricamus in et super omnibus et singulis bonis et juribus utriusque nostrum mobilibus et inmobilibus ubique habentis et habendis. Predictas itaque octo libras, sex solidos et octo denarios censuales annuales et rendales cum omni utili dominio ac pleno jure petendi, habendi, exhigendi et recipiendi ipsas, sine tamen empara vendimus vobis et vestris perpetuo pretio, videlizet, centum libras re(galium) $\mathrm{Ma}$ (ioricarum) mi(nutorum) quas a vobis confitemur nos habuisse et recepisse numerando in presencia notarii et testium infrascriptorum. Et quo servierunt et converse fuerunt ad solvendum retabu$\operatorname{lum}^{83}$ noviter factum pro ecclesia Beate Virginis Marie de Jesus (IHS) in plano presentis ville. Unde renuncia- mus excepcionis dicte vendicionis per per nos vobis non facte dicteque pecunie a vobis non habite, non recepte et non numerate. Si vero hec venditio plus dicto precio modo valet aut valebit de cetero totum id plus quicquid et quantum fuerit, damus et remittimus vobis et vestris donacione propria, simplici et irrevocabili qua ${ }^{84}$ dicitur intervivos, renunciantes scienter legi que subvenit deceptis ultra dimidiam justi precii. Constituimus nos predicta que vobis vendimus vestro vestrorumque nomine interim possidere se quasi / donech de predictis vos vel vestri possessione adepti fueritis corporalem quam liceat vobis et vestris apprehendere et adipisci vestra propria autoritate et apprehensio penes vos et vestros licite retinere et titulo et ex causa huiusmodi vendicionis damus et redimus vobis et vestris omnia loca et jura nostra omnesque voces, vices, raciones et actiones reales et personales, utiles et directas varias sive mixtas, ordinarias et extraordinarias et alias quascumque nobis et nostris in predictis pertinentes et pertinencia ac pertinere debentes et debentis quovismodo jure, titulo sive causa seu racione. Quibus juribus, locis, vocibus, vicibus, racionibus et actionibus et aliis nostris predictis valeatis vos et vestris semper libere uti agere, exercere et experiri vosque tueri et defendere judicio et extra, tam agendo quam defendendo. Mandantes serie presentis publici instrumenti vicem epistole gerentis in hac parte nobis et nostris et ceteris aliis bona nostra possidentibus quatenus de dictis octo libris, sex solidis et octo denariis censualibus et rendalibus vobis et vestris solvere, respondere et satisfacere teneamur et debamus. Quoniam ponentes vos et vestros in predictis, in locum et jus nostrum constituimus vos et vestros in ipsis veros dominos et legittimos procuratores ut in rem vestram propriam ad habendum, tenendum, possidendum, dandum, vendendum, impignorandum et alios quovismodo alienandum vestrasque vestrorum omnimodas voluntates inde libere et perpetuo faciendum quibuscumque volueritis. Et sic promittimus ea bona fide convenimus predicta qua vobis vendimus faciemus vos et vestros facere / habere, tenere et in sana pace possidere contra omnes personas, et tenemur tenerique promittimus vobis et vestris pro predictis de firma et legali evictione, necnon de omnibus dampnis, sumptibus, missionibus et expensis litis et extra littem etiam et ubique, et pro quibus omnibus et singulis sis tenendis, servandis et complendis, obligamus vobis et verstris omnia et singula bona et jura nostra et utriusque nostrum mobilia et inmobilia ubique habita et habenda, renunciantes scienter quantum ad hec omnibus juribus, legibus, sciliis, franquesiis, privilegiis, consuetudinibus et constitucionibus et aliis quibusvis quibus contra predicta nos juvare possemus quoquomodo. Actum est hov Evice, die XIIII mensis januarii anno a Navitivate Domini $\mathrm{M}^{\circ}$ D III. Sig++na nostrum Petri Tur et Bartholomei Tur predictorum qui hec laudamus, concedimus et firmamus. 
Testes huius rei sunt honorabiles Johannes Mari, vignerius, et Petris Costa, presbiter.

Dicta die.

Noverint universi quod nos, Lucianus Tur, Climens Johannis et Bartholomeus Johannis, jurati anno presenti universitatis castri, ville et insular Evice, scientes, attendentes vos, honrabilem Petrum Tur et Bartholomeum Tur Luciani, consiliarios de consilio secreto anni presentis universitatis Evice, nomine vestro proprio, die presenti et infrascripto cum publico instrumento paulo ante istur facto in posse notarii infrascripti, manulevasse ab honorabile ${ }^{85}$ Johanne Serra, filio Bernardi, ad censuale ${ }^{86}$ centum libris re(galium) $\mathrm{Ma}$ (ioricarum) mi(nutorum) que servierunt / ad solvendum retabulum noviter factum pro ecclesia Beate Virginis Marie de Jesus in plano presentis ville. Et volentes vos, dictos venerabiles Petrum Tur et Bartholomeum Tur reddere et servare indempnes a manulevamentis dicte quantitatis et a prestacione annui census euisdem. Id circo nos, dicti jurati, vice et nomine dicta universitatis et singularium de eadem, gratis et ex nostri certa sciencia promittimus et bona fide convenimus pro firmam et solemnem stipulacionem verbis legittimis conceptam, vobis, dictis Petro Tur et Bartholomeo Tur, presentibus et vestris, in manibus et posse notarii infrascripto, hec a nobis stipulatis et recipientis quod nos, dicti jurati et qui pro tempore fuerint sine dampno et missione vestri et vestrorum bonorum et rerum vestrarum, dabimus, trademus, solvemus et deliberabimus de bonis nostris propriis et dicte universitatis, dicto honorabile ${ }^{87}$ Johanni Serra et suis, termino statuto et contento juxta contractus incarricamenti dicti censualis hodie inter impsum et vos factum, omni dilacione, excepcione et diffugio proculpulsis ac vos et vestros, et bona vestra et vestrorum servabimus et reddemus indempnes et indempnia ante dampnum datum et post a prestacione et solucione annui census dictarum centum librarum. Itaquod si pro predictis aut occasione promissorum opportebit vos vel vestros aliquid dare vel solvere aut aliqua dampna, gravamina, sumptus, missiones, expensas et interesse tam in solvendo dictum censum quam in sagionibus, scripturis, advocatis, procuratoribus seu alias qualitercumque fuerint, promittimus et convenimus et pacto / vobis et vestris vero, solo, plano et simplici verbo absque testibus et juramento et judiciali tatxacione minime recepta et etiam expectata pro quibus omnibus et singulis sit tenendis et servandis et firmitter attendendis, obligamus vobis et vestris et dicto Johanni Serra et suis omnia et singula bona et jura nostra et dicta universitatis et singularium de eadem, mobilia et inmobilia privilegiata et non privilegiata $^{88}$ ubique habita et habenda. Renunciantes benefficiis novarum constitutionum et dividendarum accionum et epistole divi Adriani omnibusque aliis juribus, legibus, privilegiis, franquesiis, constitucionibus et consuetudinibus quibus contra predicta nos proprio nomine aut nomine dicte universitatis et singularium eiusdem juvare possemus aut dicta universitas et singulares juvare possent quoquomodo. Actum est hoc Evice, die quarta decima januarii anno a Nativitate Domini $\mathrm{M}^{\circ}$ quingentesimo tercio. Sig+++na nostrum Luciani Tur, Climentis Johannis et Barthomei Johannis, juratorum predictorum, qui hec laudamus, concedimus et firmamus. Testes huius rei sunt honorabiles Johannes Marí, vignerius, et Petrus Costa, presbiter.

Die prima mensis junii anno a Nativate domini MDLXXV[I $]^{89}$.

Die dictum censualle dictarum centum librarum fuit lineatum et cansellatum de voluntate Petri Serra et Johannis Serra, filii Johannis, eredes dicti quodam Johannis Serra, qui confe[ssa]runt habuise et resepise predictarum centum librarum proprietatis et totum interesse seu prorata per manus magnifici Petri Bellensat, boserii universitatis Evice presencie Benedi[ctum] Morató, notarium publicum Evice et presentibus pro testibus Antonio Tur, filio Micaellis, et Antoni Serre, filio Endrei, abitatoribus Evice. 
* Grup de recerca consolidat: Arqueologia Agrària de l'Edat Mitjana (ARAEM), 2014 SGR 741 (IP: Helena Kirchner).

1. Sobre el retaule, vegeu, sobretot: Ximo Company (1991), La pintura dels Osona: Una cruilla d'hispanismes, flamenquismes $i$ italianismes, Lleida, Pagès Editors / Edicions de la Universitat de Lleida, 2 vols. També, encara, l'obra de Chandler R. PosT (1935), A History of Spanish Painting, Cambridge, Massachusetts, Harvard University Press, VI (1), p. 170-241. I altres obres secundàries: Sebastián LóPEZ Santiago (1973), El patrimonio artístico de Ibiza, Palma de Mallorca, Instituto de Estudios Baleáricos; Gabriel Sorà Torres (1989), «El retablo de Jesús», Programa de Festes de Jesús; Joan Marí Tur (dir.) (1999), Set Segles Fa: Catàleg de béns mobles d'interès historicoartístic de l'Església d'Eivissa i Formentera, Eivissa, Consell Insular d'Eivissa i Formentera; Laura Amengual SERra (2001), «El retaule de Nostra Senyora de Jesús: estat de la qüestió», Fites, 2, p. 42-51, i

Maria Lena Mateu Prats (2006), «Jesús, retaule de la Mare de Déu de», Enciclopèdia d'Eivissa i Formentera, Eivissa, Consell Insular d'Eivissa i Formentera, 8, p. 296-298.

2. El retaule ja va ser restaurat a començament de la dècada de 1990. Vegeu María del Carmen Carretero Marco (1993), «Restauración del retablo de Jesús (Ibiza)», Pátina: Escuela Superior de Conservación y Restauración, 6, p. 156-163.

3. Chandler R. Post (1935), A History of Spanish Painting, Cambridge, Massachusetts, Harvard University Press, VI, 2, p. 170-241. Hi ha una traducció a l'espanyol de la part referida al retaule de Jesús d'Eivissa: [Joan Pons Marquès] (1939-1943), «Mr. Post y la pintura medieval mallorquina», Boletín de la Sociedad Arqueológica Luliana: Revista de Historia, Arqueología y Lulismo, XXVIII, p. 36-42. Per a l'estudi estilístic i iconogràfic, em remet a la bibliografia citada. Sobre els artistes de la família Osona, a més de les dites obres, vegeu: Luis Tramolleres BlasCO (1908), «El maestro Rodrigo de Osona y su hijo del mismo nombre», Cultura Española, IX, p. 139-156; Elías Tormo Monzó (1932), «Rodrigo de Osona, padre e hijo, y su escuela I», Archivo Español de Arte y Arqueo- logía, 8, 23, p. 101-147 i Elías Tormo Monzó (1933), «Rodrigo de Osona, padre e hijo, y su escuela II", Archivo Español de Arte y Arqueología, 9, 27, p. 153214; María José López Azorín i Vicente Samper Embiz, "Sobre pintores en el Reino de Valencia hacia la primera mitad del siglo XVI: Aportación documental», a L. Hernández Guardiola (coord.) (2006), De pintura valenciana (1400-1600): Estudios y documentación, Alacant, Instituto Alicantino de Cultura Juan Gil-Albert, p. 133-148.

4. Isidor MaCabich (1944), «De Ntra. Señora de Jesús y los primeros frailes que allí habitaron", Ibiza, 7, p. 110-112.

5. Pablo Piferrer i José María Quadrado (1888), España. Sus monumentos y artes. Su naturaleza e historia: Islas Baleares, Barcelona, Tipografía de Daniel Cortezo, p. 1.368.

6. Arxiu Històric d'Eivissa (AHE). Hemeroteca (consulta en línia), Diario de Ibiza, 4.595 (29 d'agost de 1912) i 9.413 (12 de setembre de 1919).

\section{Felip Cirer Costa (1998), El} convent dels pares dominics d'Eivissa, Eivissa, Consell Insular d'Eivissa i Formentera.

8. Arxiu Històric de la Pabordia d'Eivissa (AHPE), i Vicente FERrer Canals, Historia breve, llana y suscinta de este Convento de San Vicente Ferrer y San Jaime: Orden de Padres Predicadores de la Isla y Real Fuerza de Ibiza. Sacada de los monumentos y escritura que se contienen en su archivo por el R.P.F. Vicente Ferrer y Canals, archivero. Siendo Prior el M.R.P.F. Miguel Sala. Año 1764, editat per Felip Cirer Costa, El convent..., op. cit., p. 135.

9. Arxiu de Protocols d'Eivissa i Formentera (APEF), notari Martí Almarge, Protocol de 1674, folis 47r.-50r.

10. APEF, notari Mauro XImeNo, Protocol de 1703 a 1706, folis 79v., 80r.-v., 81r.-v., 82r.-v., 83r.

11. Ximo Company (1991), La pintura dels Osona..., op. cit., 1, p. 137.

12. Ernest Prats Garcia (2000), «Deià Tortella, Antoni - pare Gaietà de Mallorca-», Enciclopèdia d'Eivissa i Formentera, Eivissa, Consell Insular d'Eivissa i Formentera, 4, p. 113-114.
13. Pare Gaietà de Mallorca (Antoni Deià Tortella) (1751), Resumpta Histórica Geográfica y Coronológica de la isla de Iviza y su Real Fuerça, foli xxıv.

14. Isidor MACABICH, «De Ntra. Señora de Jesús...», op. cit., p. 110. Isidor MaCaBICH, Historia de Ibiza, III, p. 351.

15. Ximo Company (1991), La pintura dels Osona..., op. cit., 1, p. 137. Tina Sabater, en el seu exhaustiu estudi La pintura mallorquina del segle XV (Universitat de les Illes Balears, Palma, 2002), afirma cautelosament: «sembla ésser que foren els franciscans, establerts a la parroquial de Jesús després de 1493 i fins abans de 1512 , els responsables de la contractació del retaule», p. 400.

16. Domenico de Gubernatis (1685), Orbis seraphicus historia de tribus ordinibus a seraphico Patriarcha S. Francisco institutis, deque eorum Progressibus, et Honoribus per quatuor Mundi partes scilicet Europam, Asiam, Aphricam, et Americam: Tomus Quartus, Roma, Apud Nicolaum Angelum Tinassium Impressorem Cameralem, p. 361, 365, 382. Divisió dels franciscans en temps de Juli III citada en una butlla de Gregori XIII (15721585), pàgines 361 i 365 : «Hoc idem a Iulio III Pontifice fuisse innovatum legimus in quadam Gregorii XIII bulla, pro terrae laboris provinciae divisione quan in sequenti describemus [...] 18. Provincia Aragoniae custodias 7»; de les quals Mallorca és la quarta i conté 3 llocs: «IV. Custodia Maioricar. Habet loca 3. I. Maioricarum. 2. Minoricae, seu Civitatulae. 3. Iussae, sive Imisae». Ara bé, en la divisió, sembla que, a la de 1506 (p. 369), no hi figura Eivissa (p. 382):

«Provincia Quinta Aragonia, istos recensebat conventus, per quatuor custodias distinctos»: Aragó (12 convents), València (9 convents), Mallorca ( $«$ S. Francisci Incae, S. Francisci Maioricae, S. Mariae de Ihesu Mahonis, S. Mariae de Iesu Sollaris, S. Francisci Civitatulae»), Catalonia (8 convents).

17. El pare Pedro Sanahuja Vallverdú (Historia de la seráfica provincia de Cataluña, Barcelona, Seráfica, 1959, p. 288) reprodueix la llista de 1505 que D. de Gubernatis ofereix en el seu volum quart, p. 398-399, i en la qual no consta el convent d'Eivissa. En canvi, fa constar Eivissa en la llista de convents 
de la província d'Aragó corresponent a l'any 1334 (aprox.). En aquest cas, es tractaria del convent d'Inca, fundat efectivament el 1325 (dada del mateix P. Sanahuja, p. 81) i que el dit autor confon a l'índex toponomàstic amb Eivissa.

18. Tarsicio de Azcona (1970), «Reforma de la provincia franciscana de la Corona de Aragón en tiempos de los Reyes Católicos», Estudios Franciscanos, LXXI, p. 245-343.

19. Antoni Ferrer Abárzuza (1995), Transcripció del Llibre de determinacions del Consell, 1456-1457, Eivissa, Ajuntament d'Eivissa, p. 15.

20. AHE, Capitols de 1466. Isidor MaCABich, «De Ntra. Señora de Jesús...», op. cit., p. $110-112$.

21. Ricard Urgell HernàndeZ (2006), «La revolta forana i sus consecuencias", a Jaume GIL (coord.), Historia de las Islas Baleares, Palma, El Mundo-El Día de Baleares, 9, p. 68-83.

22. Miquel Àngel Casasnovas Camps (1998), Història de les Illes Balears, Palma, Editorial Moll, p. 207-216.

23. A. Ferrer Abárzuza (2003), "Guerra Civil catalana», Enciclopèdia d'Eivissa i Formentera, Eivissa, Consell Insular d'Eivissa i Formentera, 7, p. $98-101$.

24. AHE, Cartes reials, J.II/4-1466. Les còpies a AHE, Llibre d'actes $i$ contractes de la universitat de 1462-1478.

\section{AHE, Capitols de 1466.}

26. Francesc Xavier Torres PeTERS, «La institució de benifets i la celebració de la missa a les esglésies dels quartons i en algunes capelles de la vila d'Eivissa (segles xIv, xv i xvI)», El Pitiús 2012, p. 26-36.

27. Joan Binimelis (1927), Nueva historia de Mallorca y de otras islas a ella adyacentes, Palma, Imprenta de José Tous, vol. III, cap. xxxvi, p. 306-307. Se n'ha fet una nova edició: J. Moll i Gómez de la Tía (ed.) (2014), Joan Binimelis: Descripció particular de l'illa de Mallorca e viles, València, Publicacions de la Universitat de València, Monuments d'Història de la Corona d'Aragó, V.
28. Antoni Furió (1851), Vida del bendito Padre Fray Bartolomé Catañy, mallorquí, fundador del Santo Hospital General de la ciudad de Palma, su Juez Conservador y Delegado Apostólico, primer restaurador de la observancia de la regla seráfica en la provincia balear, Mallorca, Imprenta de Juan Guasp, p. 117.

29. Luca Waddingo Hiberno (OFM) (1735), Annales Minorum seu Trium Ordinum a S. Francisco Institutorum, 2a ed. XIII, Roma, Typis Rochi Bernabó (1a ed. 1654), p. 518-519: «Sane pro parte dilectorum filiorum incolarum, et habitatorum Minoricae et Iviçae Insularum, Majoricen. et Terraconen. dioec. nobis nuper exhibita petitio continebat, quod ipsi considerantes, quam magni et uberes fructus ex praedicationibus, monitis et exemplari vita dilectorum filiorum Fratrum domus sanctae Mariae de Angelis extra muros Majoricen. Ordinis Fratrum Minorum, sub Regulari Observantia degentium, post constructionem dictae domus Insulae Majoricen. subsecuti sunt, sperantesque, quod, si in eisdem duabus Insulis, quae Insulae Majoricen. sat propinquae, et in quibus nullae domus eorundem Fratrum existunt, aliquae domus hujusmodi pro usu et habitatione Fratrum praedictorum construerentur, similes in eis fructus, tam quo ad inimicitiarum et discordiarum inibi vigentium sedationem, quam alias dietim subsequerentur, singulas domos pro usu et habitatione Fratrum hujusmodi in singulis ipsarum Minoricae et Iviçae Insularum, libenter construi et edificari facerent, si ipsis super hoc per Sedem Apostolicam licentia concederemtur».

30. Antoni Furió, Vida del bendito Padre Fray Bartolomé Catañy..., op. cit., p. 332-333.

31. Luca Waddingo, Annales Minorum..., op. cit., p. 520-521. Sebastián López, a El patrimonio artístico de Ibiza (Instituto de Estudios Baleáricos, Palma, 1973, p. 41), proporciona la notícia, de la qual no cita la font, que l'any 1480 l'església de Jesús hauria estat entregada al prior del convent franciscà de Manresa amb la intenció que hi fundés una comunitat del seu orde. Molt probablement, es tracta d'una confusió que afecta la data i el lloc que proporciona el dit autor amb la cessió als frares dominics, de l'any 1580 i feta al prior del convent de Sant Francesc de Tor- tosa (Isidor Macabich, Historia de Ibiza, III, 351).

32. Bartolomé Escandell BoNET (1995), Ibiza y Formentera en la Corona de Aragón, Palma, Lleonard Muntaner Editor, 2, p. 417-423, esp. 418.

33. Bartolomé Escandell BoNET, Ibiza y Formentera..., op. cit., 2, p. 417-423.

34. Bartomeu Catany nasqué a Felanitx, segons sembla, i morí a Ciutat de Mallorca el 1462.

35. Vegeu-les, juntament amb algunes fotografies antigues, a $<$ www.possessionsdepalma.net>, "Convent de Nostra Senyora dels Àngels de Jesús».

36. Felip Cirer Costa, El convent..., op. cit., p. 234.

37. AHE, Llibre de clavaria de 1493-1494, foli 11v. Tot el procés de formació i transformació del pla de Vila a Ricardo González Villaescusa i Helena Kirchner (1997), «La construcció d'un espai agrari drenat andalusí al Ḣawz de la madinna de Yābisa: Anàlisi morfològica, documental i arqueològica del pla de Vila», a Miquel BARCELó (coord.), El curs de les aigües: Treballs sobre els pagesos de Yabisa (290-633H / 902-1235 $d C)$, Eivissa, Consell Insular d'Eivissa i Formentera, p. 65-90, Quaderns d'Arqueologia Pitiüsa, 3.

38. Francesc Xavier Torres Peters (2011), El capbreu dels arquebisbes de Tarragona Gonçal Ferrandis d'Hixar i el cardenal Domènech Ram (1433-1437), Eivissa, Consell Insular d'Eivissa.

39. María Dolores Tena MediAldea (2013), «Blasons a Dalt Vila: Una història cultural d'Eivissa», Eivissa, 54, p. 76-85.

40. Francesca Tur Riera (1992), El regiment de sac (Transcripció), 1454-1456, Eivissa, Ajuntament d'Eivissa, Llibre de la Cadena, 1.

41. Francesca Tur Riera, El regiment de sac, op. cit., p. 7.

42. AHE, Llibre de clavaria de 1483-1484, foli 3v. Al mateix llibre, s'hi recullen els pagaments als priors de Santa Eulària, Portmany i Sant Jordi.

43. AHE, Llibre de clavaria de 1493-1494, foli 20v. També hi ha els pagaments als priors de Sant Jordi, de Sant Antoni de Portmany i de Santa Eulària. 
44. Isidor MaсавісH, Historia de Ibiza, IV, op. cit., p. 261.

45. ARM, Lletres missives (AH679, foli 26v.). P. A. Borrás (1895-1896), «Vicariato de los franciscanos de Mallorca (1460)», Bolletí de la Societat Arqueològica Lul.liana, VI, p. 98.

46. Tarsicio de Azcona, «Reforma de la provincia franciscana...», op. cit., p. 335-343. La citació és d'ARM, Lletres missives (AH-684, folis 94v.-95r.).

47. Isidor MAСАвіCH, «De Ntra. Señora de Jesús...», op. cit., p. 110.

48. Pere Sanahuja (1935), «Monestir dels framenors observants de Lleida», Analecta Sacra Tarraconensia, 11, p. 179-202.

49. Isidor MACABICH, «De Ntra. Señora de Jesús...», op. cit., p. 110.

50. Isidor MaсAвICH, «De Ntra. Señora de Jesús...», p. 110. Del mateix 1505, Macabich (Historia de Ibiza, III, p. 346) recull unes instruccions per als preveres de l'església parroquial de Santa Maria, en les quals s'estipula el que havien de cobrar els que acudien a fer la missa a Nostra Dona de Jesús. Això podria contradir la presència franciscana si no s'interpreta com un document genèric.

51. Isidor MACABICH, «De Ntra. Señora de Jesús...», op. cit., p. 110. Existeix un llibre de clavaria sense data però corresponent a la darreria del segle xv que conté el registre del pagament al prior de Jesús: «Ítem, e pagats a n'Ernau Sera II lliures, són per lo prioratge de Nostra Dona de Ihs. II lliures».

52. Isidor MacAвich, «De Ntra. Señora de Jesús...», op. cit., p. 110.

53. AHE, Llibre de Juraria de 1534-1535, foli 21v.: «Prior de Jesús. A l'amat etc. Dau e pagau a mossèn Antoni Rosselló, prevere, prior de la iglésia de la Verga Maria de Jesús, XX sous que acostuma haver de salari lo dit prior. Sagellat etc. Scrit a XXV de maig MDXXXV».

54. Isidor MaCAвICH, «De Ntra. Señora de Jesús...», op. cit., p. 110.

55. AHE, Llibre de clavaria de 1539-1540.
56. AHE, Llibre de Juraria de 1542-1543, s. f.

57. Isidor Mасавісн, «De Ntra. Señora de Jesús...», op. cit., p. 110.

\section{AHE, Llibre de clavaria de} 1546-1547.

59. AHE, Llibre de clavaria de 1548-1549, s. f.: «Mossèn Perot Tur, prior de Nostra Dona de Jesús I lliura. dich I lliura. A VIII de juny paguí lo salari al sus dit segons alberà de mà seva». $\mathrm{A}$ un altre foli: «A X d'agost 1548 atorch haver rebut yo, Perot Tur, prevere, de vós, mestre Francesc Salvany, clavari, los vint sous que costuma donar la Universitat per mon celari de prior de la Verge Maria de Ihs., dich I lliura». Hi figuren, així mateix, els priors de Santa Eulària, Sant Antoni, Sant Jordi i Sant Miquel.

\section{Vicent Ferrer Mayans} (1997), Un memorial de la guerra contra el turc, Barcelona, Curial Edicions Catalanes, p. 82, Biblioteca Torres Amat.

61. Tarsicio de Azcona, «Reforma de la provincia franciscana...», op. cit., p. 335-343.

62. Ximo Company (1991), La pintura dels Osona..., op. cit., 1, p. 137.

63. Arxiu Històric de la Pabordia d'Eivissa (AHPE), 2.159, foli $79 r$. Publicada amb alguns defectes de lectura per I. Macabich (Historia de Ibiza, III, p. 218). En proporciono la transcripció correcta, gentilesa de Francesc Xavier Torres Peters.

\section{Francesc Xavier Torres} Peters (2005), «Aproximació a l'origen de l'església de Sant Jordi del quartó de les Salines i d'altres temples pitiüsos», Fites, 5, p. 27 40, especialment p. 40. En cita dos expedients inèdits: l'un és AHPE, S/C, Expediente formado para la reparación de la Parroquial Iglesia de Nuestra Señora de Jesús, i de l'altre diu que està sense catalogar (S/C) al mateix arxiu.

65. Agraeixo les fotografies de l'obra facilitades pel Dr. Joan Ramon Torres, tècnic de patrimoni del Consell d'Eivissa.

66. Joan Josep SERra RodríGUEZ (2000), Fortificacions rurals a l'illa d'Eivissa: Les torres de refugi predials, Eivissa, Consell d'Eivissa i Formentera / Editorial Mediterrània, p. 41.
67. Aquest temple va ser objecte d'una intervenció arquitectònica a la darreria dels anys vuitanta del segle xx. Feta amb materials contemporanis i sense un estudi seriós de com afectarien els canvis ambientals al retaule, el resultat ha estat molt negatiu.

68. Vegeu José Costa Ferrer (1934), Ibiza: Guía gráfica, Palma, Fomento del Turismo de Mallorca.

69. Les fotografies del fons de la família Cuyàs mostren que la taula fou repintada després de la Guerra Civil. També Institut CARTOGRÀfic I GeOlògiC DE Catalunya, Fotografies antigues dels Països Catalans, Fons Família Cuyàs (RF. 8811) $<$ http://cartotecadigital.icc.cat $>$. La fotografia anterior al conflicte publicada per J. Costa mostra la taula molt deteriorada.

70. AHE, Llibre d'actes $i$ contractes de la Universitat, 1499 1510 , folis $137 \mathrm{r}$. $-139 \mathrm{v}$.

71. Joan Serra figura com a clavari de la Universitat l'anyada 1456-57 (AHE, Llibre de determinacions de 1456-1457). El seu fill Joan, qui, juntament amb Pere Serra, cobrà, el 1575, els diners del censal i aquest va quedat cancel-lat, està documentat a la segona meitat del segle xvi com un personatge ric, propietari de captius i ocupant, també ell, càrrecs a la Universitat. A. Ferrer Abárzuza (2011), Captius o esclaus a Eivissa (s. XIII-XVI), UAB, tesi doctoral inèdita.

72. Miguel Falomir Faus (1996), Arte en Valencia, 14721522, València, Generalitat Valenciana, Consell Valencià de Cultura, p. 262.

73. AHE, Llibre d'actes $i$ contractes de la Universitat, 14991510, foli 103v.-105r. Gràcies a una notícia procedent del mateix llibre o manual, Francesc Xavier Torres cita l'adquisició d'unes capes pluvials, a València, pel preu de cent lliures (foli 77r.); vegeu Francesc Xavier Torres Peters, «Els bordons d'argent de Santa Maria d'Eivissa», El Pitiús 2015, p. 37-42.

74. Jerónimo Cortés (1594), Compendio de reglas breves, con el arte de hallarlas e inventariarlas, assi para las reductiones de monedas del Reyno de Valencia, Aragon, Barcelona y Castilla, como para las demás monedas 
de los otros Reynos, muy util y necessario a todo género de tratantes, con muchas preguntas $y$ respuestas de numeros, València, Herederos de Ioan Navaro, folis $54 \mathrm{v} .-55 \mathrm{r}$.

75. Totes les referències a preus d'obres provenen de Ximo Company (1991), La pintura dels Osona..., op. cit., 1, p. 43-53.

76. Frederic Aparici ha rebut un ajut econòmic de l'Ajuntament de Santa Eulària des Riu per fer una recerca sistemàtica dels protocols notarials de l'Arxiu de Protocols del Col-legi del Corpus Christi de València, amb l'objectiu d'intentar localitzar el dit contracte.
77. Ximo Company (1991), La pintura dels Osona..., op. cit., I, p. 52-53.

78. De mà diferent, al marge superior esquerre. Tot l'instrument està ratllat $\mathrm{amb}$ traços horitzontals i verticals.

79. Els dos documents que segueixen estan datats el 14 de gener de l'any 1503, de manera que l'encapçalament ha d'estar errat. La cancel·lació del censal té data de primer de juny de 1575 .

80. Hi diu «consiliarii» sobre la línia, amb crida $(\cdot / \cdot)$ al text.

81. Hi segueix «p.» ratllat.
82. Hi segueix «et.» ratllat.

83. La paraula «retabulum» hi consta corregida sobre «ratabulum».

84. Hi segueix «que» abreujat.

85. Hi segueix «Petro» ratllat.

86. Hi segueix «censuale» ratllat; al marge, CXII.

87. Hi segueix «Petro» ratllat.

88. Hi ha «Privilegiata et non privilegiata» sobre la línia.

89. Hi ha un setè guarisme que potser està ratllat. Si es dona per anullat, la data és 1575 , i si es considera que es tracta d'una unitat, 1576. 